\title{
Recent developments in the management of the pulmonary complications of HIV disease
}

\author{
David M Mitchell, Robert F Miller
}

Infection with the human immunodeficiency virus continues to spread worldwide at an alarming rate. ${ }^{1}$ Once infection with HIV has occurred treatment can only palliate the infectious and other complications of HIV disease. The development of an effective vaccine is the focus of much current research but is still awaited, whereas prevention of HIV infection raises numerous problems, and prevention programmes have not so far halted the spread of HIV. Respiratory physicians in all parts of the world will therefore continue to see increasing numbers of HIV infected individuals and to treat the respiratory complications. The purpose of these two update articles, the first of which was published in the last issue ( $p$ 305), is to review changes in perspective that have occurred regarding the pulmonary manifestations of HIV disease over the last two years since the series "AIDS and the Lung" appeared in Thorax, and also to highlight areas of importance that were not fully covered in those articles-inevitably selective as this is a wide subject and many changes have occurred, but attempting to focus on areas of particular interest or importance.

In the early and mid 1980s the diagnosis of HIV infection was regarded as the equivalent of a death sentence, with at least $70 \%$ of patients eventually developing pneumocystis pneumonia, which at that time carried a high mortality. Over the last few years there have been major changes in the patterns of lung disease seen in HIV infected individuals, which have been accounted for by several factors. Cohort studies have improved our understanding of the natural history of HIV infection and have now shown that survival with HIV infection is generally much longer than was initially thought. In a study of homosexual and bisexual men in San Francisco known to have been infected with HIV at least 11 years before, $49 \%$ had died of AIDS, leaving $51 \%$ still alive, of whom $10 \%$ had AIDS, $19 \%$ had the AIDS related complex, $3 \%$ had persistent generalised lymphadenopathy, and $19 \%$ remained symptom free. ${ }^{2}$ In a group of HIV positive haemophiliac patients followed for 11 years, $42 \%$ had developed AIDS and $41 \%$ were dead. Progression to AIDS in this group was related to the presence of P24 antigenaemia and a low CD4 cell count, ${ }^{34}$ and in homosexual and bisexual men progression to AIDS has similarly been shown to be related to serum $\beta 2$ microglobulin concentration, CD4 lymphocyte count, and HIV P24 antigenaemia. There is a considerable variability and individual variation in progression to AIDS after HIV infection and this may also be related to various host immune factors, such as serum $\operatorname{IgM}$ concentration before infection, the pattern of serum $\operatorname{IgM}$ and $\operatorname{IgA}$ at the time of seroconversion, plasma interleukin 2 receptor concentrations, and the number of circulating activated T cells. ${ }^{6}$

Over the last 10 years the prognosis of patients with AIDS has generally improved. A major measure accounting for this has undoubtedly been the widespread introduction of zidovudine, which delays the progression of HIV disease, and further improvement may accrue from the introduction of other antiviral agents. A further reason for improved prognosis has been better education of patients, resulting in earlier presentation with clinical complications, greater emphasis on outpatient surveillance to detect early disease, and better treatment of opportunist infections by more skilful and experienced doctors. ${ }^{78}$ Increasing use of both primary and secondary prophylaxis for pneumocystis pneumonia and prophylaxis for tuberculosis and pneumococcal infection have also been beneficial. ${ }^{9}$

The first article discussed advances in the management of pneumocystis pneumonia, and this article will deal with changes that have occurred in strategies for the management of opportunist infections and neoplasms that occur in the lung in HIV infected patients. Since the "AIDS and the Lung" series in Thorax there have been no changes in recommendations for sterilisation of bronchoscopes or infection control procedures.

\section{Respiratory tract infections and bacterial} pneumonia

It is now well established that pyogenic bacterial pneumonia occurs with greater frequency in HIV infected individuals than in normal individuals. ${ }^{10-13}$ The most commonly isolated organisms are Streptococcus pneumoniae and Haemophilus influenzae ${ }^{14}$ but Branhamella catarrhalis infection is also seen and severe pneumonia with Staphylococcus aureus and Gram negative bacteria may also occur, particularly in the later stages of AIDS. These 
infections may occur with rapid onset associated with a septicaemia in a severely ill patient, but generally they respond well to appropriate antibiotics. There is, however, a tendency to relapse after successful treatment. It is therefore important to bear the possibility of pyogenic bacterial pneumonia in mind with a severely ill HIV infected individual, and when an antibiotic is being selected to consider the possibility of a $\beta$ lactamase producing organism. In one study of 132 consecutive respiratory episodes in 101 patients 71 had a prior AIDS defining illness and 30 were merely HIV seropositive; 57 patients were intravenous drug users and 34 were homosexual or bisexual men. Sixty episodes $(45 \%)$ were due to bacterial pneumonia and 36 episodes $(27 \%)$ were due to pneumocystis pneumonia. Pathogens identified were mainly Streptococcus pneumoniae and Haemophilus influenzae. Chest radiographs in patients with bacterial pneumonia were often unusual; in $47 \%$ they mimicked pneumocystis pneumonia (showing diffuse reticulonodular shadowing) and 15\% had focal reticulonodular shadowing. This study showed a relative reduction in frequency of pneumocystis pneumonia by comparison with bacterial infection, but this may have been due to the large number of drug users, reflecting the dual effects of intravenous drug use and HIV infection. ${ }^{15}$ In a recent study of homosexual men in London ${ }^{16}$ bacterial pneumonia was relatively scarce (one episode per eight episodes of pneumocystis pneumonia), being more common in patients with advanced AIDS and neutropenia. Streptococcus pneumoniae, Staphylococcus aureus, and Haemophilus influenzae were isolated.

The increased susceptibility to bacterial pneumonias in HIV positive patients may be related to abnormalities in antibody production. ${ }^{17}{ }^{18} \mathrm{HIV}$ infected $\mathrm{T}$ cells may have reduced ability to activate $B$ cells, thus reducing new antibody production and resulting, in turn, in reduced "opsonisation" of capsulated bacteria. Despite this some authorities now recommend that all HIV infected individuals should be immunised with polyvalent pneumococcal polysaccharide vaccine. ${ }^{919}$

HIV infected individuals are also more susceptible to upper respiratory tract infections, as well as having an increased tendency to develop viral pneumonitis caused by herpes simplex and herpes zoster. ${ }^{2021} \mathrm{~A}$ recent study showed that self reported upper respiratory tract infections (colds, sore throats, sinusitis) at biannual clinic visits were more common among HIV positive homosexual men who did not have AIDS than in an HIV negative control group. The peak incidence for upper respiratory infections in this group of patients was during the winter months, the peak incidence for pneumocystis pneumonia occurring four months later. ${ }^{22}$

\section{Primary pulmonary hypertension}

This rare condition has recently been reported to occur amongst AIDS patients. ${ }^{1523}$ In a recent study of 74 patients with various cardiopulmonary complaints, six $(8 \%)$ had pulmonary hypertension not obviously related to intrinsic heart disease, thromboembolism, or primary lung disease. At necropsy two of these patients had plexogenic pulmonary arteriopathy. The authors conclude that from their cohort of patients the incidence of primary pulmonary hypertension was $0.5 \%$. The aetiology remains unknown, but possibly HIV or another virus is concerned. ${ }^{25}$

\section{Cytomegalovirus virus}

Cytomegalovirus infection in HIV infected patients is common and is a well documented cause of retinitis, encephalitis, colitis, adrenalitis, and radiculopathy in these patients. In patients with renal allografts and bone marrow transplants cytomegalovirus may cause pneumonitis on an immunopathogenic basis, which is frequently fatal. ${ }^{26}$ In HIV seropositive individuals there is clinical evidence that previous cytomegalovirus infection may hasten progression to AIDS. ${ }^{3}$ Laboratory studies have shown that, in cell culture, coinfection with cytomegalovirus stimulates HIV replication in vitro. $^{27}$ The immediate early gene of cytomegalovirus directly stimulates HIV gene expression. ${ }^{28}$ Perhaps therefore coinfection with cytomegalovirus could amplify the effects of HIV infection in the lung. Cytomegalovirus infection of human fibroblast cells has been shown to upregulate cellular nuclear factors within these cells, with the resultant stimulation of HIV1 long terminal repeat transcription. ${ }^{29}$ Cytomegalovirus was initially thought to be an important cause of pneumonitis in patients with AIDS. For example, in a necropsy study of patients dying with AIDS there was a relation between a high density of cytomegalovirus inclusion bodies and surrounding lung damage, though it was difficult to assess the precise role of cytomegalovirus because of copathogens, such as Pneumocystis carinii or bacteria, which were almost invariably present. ${ }^{30}$ It has become clear over the last few years that cytomegalovirus pulmonary infection is only rarely present in the absence of other pathogens in patients with AIDS who have pulmonary disease and that its presence does not adversely affect outcome and survival. ${ }^{31}{ }^{32}$ For example, cytomegalovirus was the sole pulmonary pathogen isolated in only six out of $166(4 \%)^{31}$ and two of $60(3 \%)^{33}$ patients with AIDS presenting with respiratory disease. Cytomegalovirus is extremely common in patients with AIDS, being isolated in bronchoalveolar lavage fluid in $37-58 \%$ of all those presenting with respiratory illness, ${ }^{33-36}$ but its presence does not seem to affect survival adversely. ${ }^{37}$ Furthermore, specific anti-cytomegalovirus treatment with fosphonoformate (Foscarnet) for presumed cytomegalovirus pneumonitis in patients with AIDS does not appear to improve outcome, ${ }^{38}$ as would be expected if cytomegalovirus were causing the pneumonitis. Recently, in a series of over 100 patients with AIDS presenting with first episodes of pneumocystis pneumonia, the presence or absence of cytomegalovirus in 
culture and its quantification made no difference in terms of short term recovery from the acute pneumonic episode or to long term survival. ${ }^{39}$ On the current evidence, the carriage of cytomegalovirus in the lung does not seem to be related to respiratory disease in patients with AIDS. This is in sharp contrast to the ability of cytomegalovirus to cause fatal pneumonitis in patients with other categories of immunodeficiency and to cause disease at other sites in patients with AIDS-or indeed to activate HIV in vivo.

\section{Tuberculosis}

In the early years of the AIDS era tuberculosis was not regarded as a particular problem, but over the last few years it has become clear that tuberculosis is of major importance as an opportunist infection in HIV disease, particularly in certain parts of the world and among certain groups of patients with HIV disease. Although tuberculosis at the present time is not a major problem in the context of HIV disease in the United Kingdom or in the rest of Europe, there are still grounds for great concern about the interaction of HIV with tuberculosis. This is because in developing countries, particularly in Africa, where there is a high prevalence of tuberculosis, it behaves as an opportunist infection in patients infected with HIV. Unlike all the other opportunist infections that characterise AIDS, tuberculosis is infectious for normal individuals. Tuberculosis is also a potent stimulus to cell mediated immunity and so may speed up the natural history of HIV disease. The incidence of tuberculosis is currently increasing in the United States, and this is directly attributable to the effects of HIV in certain populations. Although no increase has occurred yet in Britain, the unpredictable features of the HIV epidemic among heterosexuals, migrants, and intravenous drug users certainly do not offer grounds for complacency, so that vigilance is required. In view of the overall importance of tuberculosis in HIV disease, some of its features will be reviewed here. The detailed epidemiology has recently been extensively reviewed, so only a brief account will be given. ${ }^{40-42}$

HIV is now the most important risk factor for the development of tuberculosis, and the incidence of tuberculosis in HIV disease depends on the overlap between the population infected with HIV and the population infected with tuberculosis. ${ }^{41}$

\section{TUBERCULOSIS IN THE UNITED STATES}

After the general decline in tuberculosis, for the first time in 1986 there was a slight increase of $1.7 \%$ in the incidence of tuberculosis in the United States. ${ }^{434}$ It is now well established that tuberculosis causes increased morbidity and mortality in HIV infected individuals. ${ }^{456}$ Overall, $4 \cdot 6 \%$ of all patients with AIDS so far in the United States have developed clinical tuberculosis ${ }^{43}$ but the incidence is much higher in certain ethnic groups. In Florida $60 \%$ of Haitian patients with AIDS also had tuberculosis. ${ }^{47}$ In New York $28 \%$ of drug users with AIDS also had tuberculosis, ${ }^{48}$ whereas in San Francisco $12 \%$ of non-Asian patients with tuberculosis also had AIDS. ${ }^{49}$ In New Jersey the change in mortality from tuberculosis for the young adult population from 1979 to 1981 and from 1985 to 1987 has shown that groups with the highest incidence of AIDS also have the highest risk of death from tuberculosis, showing a clear association between HIV disease and tuberculosis. ${ }^{50}$ In a case controlled study among Haitians, $24 \%$ of patients with tuberculosis were HIV positive, whereas only $3 \%$ of the control group were HIV positive. The increased risk of tuberculosis in HIV positive young adults was $15 \cdot 7 \% .^{51}$ Tuberculosis complicating HIV disease is mainly a result of the reactivation of latent infection, though primary infection and secondary exogenous infection undoubtedly also occur. In a prospective study of intravenous drug users in New York $14 \%$ of the HIV seropositive group who were also tuberculin positive developed clinical tuberculosis over two years, whereas only $0.3 \%$ of those who were tuberculin negative developed tuberculosis, suggesting that tuberculosis in this group was largely due to reactivation. ${ }^{52}$ This study also showed that $8 \%$ of individuals infected by tuberculosis (positive tuberculin test) and HIV developed clinical tuberculosis each year.

\section{TUBERCULOSIS IN AFRICA}

In Africa tuberculosis is the most important pulmonary complication of AIDS. ${ }^{53}$ HIV infection has led to large increases in tuberculosis in central and east African countries, resulting in significant problems for disease control. In these countries the problem arises as there is a significant overlap in the populations at risk of the two infections. From $17 \%$ to $55 \%$ of all Africans with tuberculosis are also HIV seropositive. ${ }^{42}$ HIV seropositivity rates vary widely from region to region. In rural Uganda $6 \%$ of the population are estimated to be HIV seropositive, but in Kampala overall $17 \%$ of the population are seropositive-and in certain groups in the city, including prostitutes, up to half are seropositive. ${ }^{5455}$ In a recent study $66 \%$ of patients with tuberculosis in Kampala were HIV seropositive. ${ }^{56}$ In Zaire a link between HIV and tuberculosis has also been established. ${ }^{57}$ In Kinshasha it has been estimated that $70 \%$ of the adult population have been infected with tuberculosis, ${ }^{5859}$ whereas only $5-7 \%$ of women attending antenatal clinics are HIV seropositive. ${ }^{60}$ The link between HIV and tuberculosis has again been shown in a recent cohort study of women in Zaire, where $7.6 \%$ of the HIV seropositive group had tuberculosis whereas only $0.3 \%$ of the seronegative group had tuberculosis (relative risk 26). ${ }^{61}$ This association has also been found in Burundi. ${ }^{62}$

\section{TUBERCULOSIS IN THE UNITED KINGDOM}

The relation between HIV infection and tuberculosis has been described in the UK, though actual numbers remain small. Of 207 patients with AIDS, $6 \%$ developed tuber- 
culosis at some stage during the clinical course. ${ }^{63}$ Notifications for tuberculosis increased by $1.5 \%$ in 1988 by comparison with 1987 , and by $5.3 \%$ in 1989 by comparison with $1988 .^{64}$ This increase, however, was due not to HIV disease but to other factors, and in 1990 there was a fall in the notification rate. Overall, only $4 \%$ of patients reported to have AIDS in the UK have developed tuberculosis, and only $1 \%$ of all cases of AIDS are in individuals of Asian or oriental ethnic origin. There is therefore very little overlap between the two risk groups at the moment; caution is required, however, as a recent study from inner London has shown a substantial increase in tuberculosis among HIV positive white men below 55 years of age. ${ }^{65}$

\section{CLINICAL ASPECTS}

Tuberculosis may precede the development of AIDS, may be diagnosed at the same time as a diagnosis of AIDS is made, or may occur at any time during established AIDS. Extrapulmonary tuberculosis in an HIV seropositive individual is regarded as an AIDS defining diagnosis. ${ }^{66}$ The clinical pattern of tuberculosis in HIV disease is related to the stage of HIV disease at which tuberculosis occurs. Early in the course of HIV disease, when cell mediated immunity is relatively well preserved, tuberculosis may resemble the characteristic adult postprimary form of the disease; whereas if tuberculosis occurs late, when cell mediated immunity is destroyed, the clinical pattern tends to resemble that of primary infection. ${ }^{67}$ Worldwide, perhaps as many as half of all patients who are HIV seropositive who present with tuberculosis have no other symptoms or signs of HIV disease. It is therefore important to consider carefully whether to test for HIV in all new cases of tuberculosis. ${ }^{41}$

Later in the clinical course of HIV disease tuberculosis frequently presents with nonspecific features, including fever, weight loss, fatigue, and lymph node enlargement, with or without cough. Patients with low CD4 lymphocyte counts $\left(<0.15 \times 10^{9} / 1\right)$ tend to present with extrapulmonary disease as well. Overall in the United States $60-70 \%$ of all cases of tuberculosis in HIV seropositive individuals have extrapulmonary features, whereas by contrast in the general population of the United States (that is, HIV seronegative individuals) only $16 \%$ of tuberculosis cases have extrapulmonary features. ${ }^{47-49}$ Common sites of extrapulmonary disease include bone, pericardium, peritoneum, lymph nodes, central nervous system, liver, and bone marrow; and miliary disease is also common. Over $80 \%$ of patients from sub-Saharan Africa with pericardial or pleural tuberculous disease were found to be HIV seropositive. ${ }^{689}$ Disseminated miliary tuberculous disease in patients with AIDS is well recognised. ${ }^{70}$ This presentation of tuberculosis tends to take a fulminating course and carries a high mortality. Histological examination of material from sites of disease reveals numerous acid fast bacilli and a non-reactive histological pattern with poor granuloma formation and extensive necrosis.
Chest radiographs commonly show various features that differ from those of typical adult disease. Up to $10 \%$ of chest radiographs are normal. ${ }^{40}$ Hilar and mediastinal adenopathy is more common than in typical adult disease, as are miliary mottling and pleural effusion; whereas upper zone infiltrates and cavities are relatively unusual. ${ }^{497172}$ Results of tuberculin testing on theoretical grounds will depend on the individual's residual cell mediated immunity and, when this is poor, false negative tuberculin reactions are likely to occur; there are, however, no data stratifying the results of tuberculin tests with CD4 lymphocyte counts. In one combined series of 193 patients with tuberculosis $37 \%$ had a greater than $9 \mathrm{~mm}$ tuberculin reaction to 5 tuberculin units,${ }^{40}$ but in a further small study only two of $29(7 \%)$ had a positive reaction. ${ }^{48}$

Sputum may not be available for examination and if present may be negative on smear and culture. ${ }^{69}$ In one survey of 131 cases of tuberculosis in HIV seropositive individuals $48 \%$ had positive sputum smears and $67 \%$ were culture positive. ${ }^{40}$ In a further study $48 \%$ of HIV seropositive patients with tuberculosis had a positive smear whereas $81 \%$ of an HIV negative control group had a positive smear. ${ }^{73}$ In patients with absent or tuberculosis negative sputum blood culture may provide the diagnosis, particularly in patients who already have established AIDS. In one study blood culture was positive in $26 \% .^{74}$

In a series of $18 \mathrm{HIV}$ positive patients with culture positive tuberculosis in the UK four patients had tuberculosis diagnosed before AIDS, eight further patients had the diagnosis made at the same time as the diagnosis of AIDS, and two developed tuberculosis during the course of AIDS. A further patient died of septicaemia and the remaining three patients were still free of AIDS. Only five of these patients had a positive sputum smear or culture, $11(61 \%)$ had pulmonary disease only, and three of the seven with extrapulmonary disease had pulmonary disease as well. Only one of these patients had cavities on the chest radiograph, whereas six had a pleural effusion. ${ }^{75}$ In a study of $19 \mathrm{HIV}$ positive patients with tuberculosis six had pulmonary disease and four of 13 with extrapulmonary disease also had pulmonary disease. In six patients tuberculosis was diagnosed before the diagnosis of AIDS and in a further nine it was the AIDS defining diagnosis. ${ }^{65}$

\section{TREATMENT}

The clinical response to standard treatment with isoniazid, rifampicin, and either pyrazinamide or ethambutol is generally good, but overall survival is poor. One factor to account for this may be that tuberculosis is thought to accelerate the natural history of HIV disease. ${ }^{63}$ Further follow up studies will be required to establish the optimal duration of treatment. At the moment there is agreement that treatment should continue for at least six months and that isoniazid prophylaxis for life is probably desirable to prevent relapse. In one study of 125 treated patients who generally had a good 
response to treatment $18 \%$ had an adverse drug reaction, drug reactions being generally more common in HIV positive individuals anyway. ${ }^{76}$ Rifampicin interacts with ketoconazole, itraconazole, and fluconazole, reducing serum azole concentrations. Ketoconazole also inhibits absorption of rifampicin and this must be borne in mind when patients are taking these drugs. ${ }^{77}$ Although response to treatment is usually satisfactory, mortality remains high. For example, in one series death occurred in $32.5 \%$ of patients with tuberculosis who were also HIV seropositive, compared with only $1.5 \%$ of seronegative patients, ${ }^{78}$ and in another series within one year of diagnosis of tuberculosis $31.3 \%$ of HIV seropositive patients had died compared with $4.4 \%$ of seronegative patients. ${ }^{59}$ Primary drug resistance is so far not a major problem, having occurred in only one of 13 cases. $^{63}$

\section{PROPHYLAXIS AND TUBERCULIN TESTING}

The efficacy of chemoprophylaxis in the control of tuberculosis is well established, but data are limited in the context of HIV disease. Of 13 tuberculin positive patients who were HIV seropositive, none developed tuberculosis while taking isoniazid. ${ }^{52}$ Chemoprophylaxis may be difficult to implement in developing countries, so that reliance may have to be placed on case finding and treatment. ${ }^{41}$ In the United States tuberculin testing of all HIV seropositive individuals is recommended, though inevitably there will be some false negative results. All with a positive reaction of more than $5 \mathrm{~mm}$ ( 5 tuberculin units) should receive isoniazid chemoprophylaxis for at least one year. ${ }^{5279}$

\section{PREVENTION AND CONTROI}

BCG vaccination theoretically could protect against tuberculosis by preventing primary infection before infection by HIV and thus prevent reactivation occurring. There are, however, no data to support this hypothesis, and it is important to remember that BCG depends on an intact immune system to provide protection. This clearly raises problems when immunisation is being considered for children who may already be HIV seropositive. A case of disseminated BCG infection after vaccination of a patient with AIDS has been reported ${ }^{80}$ and so BCG is not recommended for patients with symptomatic HIV disease. ${ }^{81}$ Because of uncertainties regarding the impact of HIV on tuberculosis in the UK the Joint Committee on Vaccination and Immunisation has recommended continuation of the BCG programme in schools until $1995-6 .^{82}$ Clearly prevention and control will continue to rely very heavily on the identification and treatment of those with active disease as well as the identification and treatment of infected contacts. HIV seropositive patients with tuberculosis are probably just as infectious as seronegative patients. ${ }^{7183}$ Of 18 HIV seropositive contacts of an HIV seropositive index case, eight developed tuberculosis, seven within 60 days of contact. The index case had a normal chest radiograph and respiratory samples were smear negative, the diagnosis being established after culture of a transbronchial biopsy specimen. Tuberculosis was more likely to develop in contacts with low CD4 counts. ${ }^{84}$ Multidrug resistant tuberculosis has been transmitted to health care workers within an institution from an HIV seropositive case. $^{85}$

\section{Mycobacterium avium-intracellulare infection}

Of the non-tuberculous mycobacteria, Mycobacterium avium-intracellulare is by far the most common cause of infection in HIV positive patients. Although $M$ aviumintracellulare is not a pathogen specific to the lung in patients with AIDS (in fact it usually causes systemic infections), as it is a mycobacterial infection respiratory physicians are likely to be concerned in the management of these patients; so a brief review of recent developments will be presented here. $M$ aviumintracellulare is common in the environment, being present in soil, water, and food, thus making its isolation from non-sterile sites in man difficult to interpret. It is a low virulence pathogen and a rare cause of slowly progressive pulmonary disease in patients with pre-existing lung disease, particularly healed fibrotic tuberculosis. Before the advent of AIDS, disseminated infection with $M$ avium-intracellulare was extremely rare $^{86}$ but in patients with AIDS infection with $M$ avium-intracellulare is extremely common, $15-50 \%$ of patients with AIDS developing disseminated infection at some stage before death. ${ }^{87-89}$ Disseminated infection with $M$ avium-intracellulare tends to occur at the end of the natural history of HIV disease, being diagnosed 7-15 months after the diagnosis of AIDS in most cases, at a time when cell mediated immunity is severely impaired. In one series the mean CD4 lymphocyte count was below $0.06 \times 10^{9} / 1$ in AIDS patients with disseminated $M$ avium-intracellulare infection. ${ }^{419091}$ It was initially thought that as $M$ avium-intracellulare is common in the environment it tended to colonise patients with AIDS and did not cause appreciable clinical disease. Recent studies have shown that disseminated $M$ avium-intracellulare infection not only reduces survival but causes clinical disease..$^{82}$ Furthermore, the presence of $M$ aviumintracellulare in non-sterile clinical samples may be relevant. In a recent study $8.8 \%$ of AIDS patients had it isolated from respiratory specimens, whereas it was present in only $0.3 \%$ of a control group..$^{93}$ The authors concluded that the presence of $M$ avium-intracellulare in patients with AIDS is not due to environmental contamination but is a result of a tendency for them to become colonised by $M$ aviumintracellulare. This may be important as it has been suggested ${ }^{91}{ }^{94}$ that disseminated infection may be prevented by early treatment at the stage when $M$ avium-intracellulare is isolated only from the respiratory tract. Probably colonisation precedes disseminated infection. Whereas respiratory disease is fairly rare, abdominal symptoms are common, and so it is now thought that the most likely entry site is 
the gastrointestinal tract. ${ }^{89} 95$ Common sites of disease in disseminated infection are lymph nodes, liver, spleen, and bone marrow. $M$ avium-intracellulare can frequently be cultured from blood, bronchoalveolar lavage fluid, urine, and aspirates and biopsy specimens from the gastrointestinal tract. ${ }^{95}$ The typical histological picture is of large numbers of histiocytes containing numerous acid fast bacilli with minimal inflammatory or granulomatous reaction. The absence of extensive tissue damage in the presence of very large numbers of acid fast bacilli has in the past led to the suggestion that $M$ avium-intracellulare may not be an important cause of mortality in patients with AIDS, but clinical evidence no longer supports this view. 969

\section{CLINICAL PRESENTATION AND DIAGNOSIS}

Disseminated infection most frequently presents with non-specific symptoms and signs with fever, night sweats, weight loss, anorexia, and malaise. Anaemia is frequent and abdominal features are common, with hepatosplenomegaly, chronic diarrhoea, malabsorption, and pain. Retroperitoneal lymphadenopathy may be seen. In the thorax mediastinal adenopathy is relatively common and pneumonic consolidation may occur..$^{9499}$ In the early 1980 s disseminated $M$ aviumintracellulare infection was very often not treated as it was thought that the infection did not affect prognosis and treatment was undertaken only if clinical features clearly related to the infection. There is now evidence that this is not the case. For example, in one study where patients with AIDS were stratified according to their CD4 lymphocyte count those with disseminated $M$ avium-intracellulare infection had a median survival of four months, whereas patients without disseminated infection had a median survival of 11 months. ${ }^{100}$

The diagnosis of disseminated $M$ aviumintracellulare infection may be missed unless the diagnosis is considered. The differential diagnosis for the non-specific features is wide in patients with AIDS, who have often been ill for some time and who may have a wide range of other opportunist infections and tumours to account for their symptoms. If the diagnosis is considered, however, then it is relatively easy to confirm it as large numbers of acid fast bacilli will be visible in aspiration or biopsy material from lymph node, liver, or bone marrow. Blood cultures are positive in $60-100 \%$ of cases subsequently confirmed at necropsy, and clinical samples from non-sterile sites (urine, respiratory secretions, etc) are frequently positive also. It has been suggested that two or more blood cultures should be positive before a diagnosis of disseminated $M$ aviumintracellulare infection is made. 8899 Blood culture as a diagnostic tool has been enhanced with the use of the Dupont isolator (Dupont, Wilmington, Delaware, USA), which lyses blood cells and thus releases intracellular organisms before culture, and the BACTEC (Johnson Laboratories, Towson, Maryland, USA) system, which allows early detection of positive cultures at a mean of 11 days. ${ }^{101}$

\section{TREATMENT}

Treatment of $M$ avium-intracellulare infection in patients without AIDS remains difficult and controversial, a consensus view being hampered by the absence of clinical trials and problems with the methods and interpretation of sensitivity tests. ${ }^{102-104}$ In patients with AIDS early studies with standard antimycobacterial agents in small numbers of patients failed to show a worthwhile clinical response. ${ }^{88}$ Recently several drug combinations have been shown to be efficacious in terms either of reducing mycobacteraemia or of symptomatic improvement. In a small study a combination of ethambutol, ansamycin (rifabutin), clofazimine, and isoniazid resulted in improvement in symptoms and mycobacteraemia. ${ }^{94}$ With the same drug combination symptoms improved in 18 out of 25 patients and mycobacteraemia ceased in 22 out of 25 patients. ${ }^{99}$ A different combination, consisting of ethambutol, rifampicin, ciprofloxacin, and amikacin, resulted in useful symptomatic improvement and a fall in mycobacteraemia. ${ }^{98}$ A further regimen with proved efficacy, which has the advantage of consisting of oral drugs only, is ethambutol, rifampicin, ciprofloxacin, and clofazimine. ${ }^{100}$

Recent interest in the new macrolide antibiotics clarithromycin and azithromycin has stimulated preliminary clinical studies. ${ }^{105}$ Oral azithromycin resulted in substantial reductions in mycobacteraemia as well as resolution of fever and night sweats in most patients treated. ${ }^{106}$ These studies provide some grounds for optimism for the treatment of disseminated $M$ avium-intracellulare infection, but it should be remembered that all these trials have been carried out on very small numbers of patients and are uncontrolled. Treatment may have to be undertaken for substantial periods, the potential benefits being offset by the toxicity profile of most of these multiple drug regimens. As disseminated $M$ avium-intracellulare infection is very common in patients with AIDS and contributes to mortality, it has been suggested that early treatment before dissemination has occurred, or even prophylactic treatment, may be warranted. ${ }^{94}$

\section{Kaposi sarcoma}

In the previous series of articles little space was devoted to Kaposi sarcoma, but since that time it has become clear that intrathoracic Kaposi sarcoma may account for considerable pulmonary disease in patients with AIDS. At initial diagnosis Kaposi sarcoma is found in up to a quarter of reported cases of AIDS ${ }^{107}$ Epidemic AIDS related Kaposi sarcoma has several features, including a tendency to originate at multicentric sites, to affect many organ systems, and to run an aggressive clinical course, so that although many patients with Kaposi sarcoma in fact die of opportunist infections a proportion, particularly if it affects the lungs, will actually die from the tumour itself. Another interesting feature of Kaposi sarcoma in relation to AIDS is its predilection for the risk group of homosexual and bisexual men. Thus 
in the United States $95 \%$ of all AIDS related Kaposi sarcomas are in homosexual and bisexual men; overall $40 \%$ of homosexual men with AIDS will develop Kaposi sarcoma, whereas only $4 \%$ of intravenous drug abusers with AIDS develop it and the condition is very rare in haemophiliacs. ${ }^{108} 109$ The clinical features of pulmonary Kaposi sarcoma have already been well described. ${ }^{110-113}$ It is the commonest of the non-infectious complications in homosexual and bisexual men with AIDS and in this group it is the commonest non-infectious pulmonary manifestation of AIDS. Almost all patients with pulmonary Kaposi sarcoma have evidence of mucocutaneous or lymph node Kaposi sarcoma at other sites; but primary pulmonary Kaposi sarcoma, though very rare, has been described. ${ }^{114} 115$ Pulmonary Kaposi sarcoma is very often asymptomatic, but the clinical problem is always to decide whether the patient is suffering solely from pulmonary Kaposi sarcoma or whether an opportunist infection is also present.

Within the chest Kaposi sarcoma can affect the pulmonary parenchyma, the bronchi, the pleura, and the hilar and mediastinal lymph nodes. The sarcoma occurs in the upper oropharynx in about $20 \%$ of cases but is rarely a major clinical problem, ${ }^{113}$ whereas in the lower pharynx and larynx it may produce life threatening airway obstruction. ${ }^{116}$ Cardiac Kaposi sarcoma is only rarely clinically apparent, but in up to $30 \%$ of cases of Kaposi sarcoma asymptomatic subepicardial deposits are found at necropsy. Pericardial sarcoma with effusion is very rare in patients with AIDS and endocardial and myocardial sarcomas have not been described. ${ }^{117}$ Although pulmonary Kaposi sarcoma is relatively common, most morbidity and mortality occur from opportunist infection, and this must be carefully sought. In 20 $30 \%$ of patients with pulmonary Kaposi sarcoma no concomitant cause for pulmonary disease is found, the diagnosis being made at necropsy. Respiratory failure may complicate pulmonary Kaposi sarcoma as a result of progressive massive pulmonary consolidation, obstruction of the trachea or major bronchi by sarcoma, pulmonary oedema from lymphatic obstruction due to sarcoma of mediastinal lymph nodes, or massive uncontrolled pleural effusions. Chest radiographs most frequently show non-specific features, but some clues to the diagnosis may be present. In a review of 77 patients from various series ${ }^{113} 62 \%$ had bilateral interstitial or alveolar infiltrates on the chest radiograph, $15 \%$ bilateral nodular infiltrates, and $9 \%$ unilateral infiltrates. Twenty six per cent had hilar or mediastinal lymph node enlargement, $42 \%$ had pleural effusion, and $25 \%$ had septal (Kerley B and C) lines. The presence of mediastinal adenopathy or pleural effusion provides the clue to diagnosis as these features are extremely uncommon in pneumocystis pneumonia. Routine pulmonary function tests may show reduced lung volumes with reduced transfer factor and sometimes airflow obstruction is evident if there is extensive sarcoma in the airways. These changes are sensitive but not specific for pulmonary Kaposi sarcoma. ${ }^{110} 118$
Fibreoptic bronchoscopy remains the most sensitive technique available for the diagnosis of pulmonary Kaposi sarcoma, yet only $45 \%$ of patients with pulmonary Kaposi sarcoma have visible endobronchial lesions, which typically consist of multiple red or purple, flat or raised lesions that tend to occur at segmental orifices in the main bronchi and the trachea. ${ }^{113119}$ As most patients have lesions at other sites, which will have been biopsied before bronchoscopy, bronchoscopic biopsy is usually regarded as unnecessary. Biopsy is generally safe, though in one small series $30 \%$ had appreciable haemorrhage. ${ }^{120}$ Diagnostic yield from biopsy is generally poor (generally $10-20 \%$ ), probably because of the submucosal location of the lesions. Transbronchial biopsy similarly produces low diagnostic yields (13\%), because of the patchy distribution of the disease. For the histopathologist it may be difficult to make a diagnosis of Kaposi sarcoma on the basis of a bronchial biopsy specimen. Kaposi sarcoma lesions are composed of spindle like cells and blood vessels; some of the blood vessels are quite normal in appearance, but others are more slit like and may have no endothelial lining. Surprisingly, there may be infrequent or no features of malignancy. Rarely nuclear atypia or mitoses are seen, but appearances similar to normal reactive fibrous tissue formation are more usual. Routine bronchoscopy with bronchoalveolar lavage is, however, important for excluding concomitant opportunist infections. Open lung biopsy has a diagnostic yield of $75 \%$ and here also some false negatives occur as a result of the patchy distribution of the disease. Only rarely is open lung biopsy indicated and on the whole this invasive diagnostic technique should be avoided in view of the very poor overall prognosis of this group of patients.

Occult alveolar haemorrhage has frequently been described at necropsy and in open lung biopsy specimens from patients with pulmonary Kaposi sarcoma. It has been suggested that the presence of haemosiderin laden macrophages in bronchoalveolar lavage fluid (stained by Perl's iron stain) is strongly suggestive of occult alveolar haemorrhage caused by pulmonary Kaposi sarcoma. ${ }^{121}$ One study found evidence of occult alveolar haemorrhage in bronchoalveolar lavage fluid from six of nine patients with pulmonary Kaposi sarcoma. This was thought to be highly specific for Kaposi sarcoma as haemosiderin laden macrophages were not detected in lavage fluid from 75 HIV positive patients with other diagnoses, including tuberculosis and cytomegalovirus pneumonitis. Another study has suggested that the presence of occult alveolar haemorrhage in bronchoalveolar lavage fluid is not helpful in the diagnosis of Kaposi sarcoma. ${ }^{122}$ Sixty three HIV positive patients underwent bronchoscopy and bronchoalveolar lavage for diagnosis of respiratory episodes. Twenty three patients had Kaposi sarcoma; 16 had occult alveolar haemorrhage (including two patients with normal bronchoscopic appearances in whom the diagnosis of Kaposi sarcoma was made at necropsy (mean 10.4 weeks later). Forty patients had alternative diagnoses, including 
pneumocystis pneumonia in 24 and bacterial pneumonia in 11 patients. Eighteen of this group of patients had occult alveolar haemorrhage, indicating that this finding was nonspecific in HIV positive patients with respiratory episodes.

Aspiration of a pleural effusion normally reveals a serosanguineous exudate, though clear fluid may be obtained in some cases. Transudates have been reported in hypoalbuminaemic patients. Closed needle pleural biopsy rarely provides diagnostic information as the parietal pleura is seldom affected in pulmonary Kaposi sarcoma. Pleural effusion tends to be a relatively late manifestation of pulmonary Kaposi sarcoma.

\section{TREATMENT}

Pulmonary Kaposi sarcoma is difficult to treat as it represents either more aggressive systemic disease or late stage disease. Early studies showed that some palliation could be achieved with single agent etoposide, vincristine, vinblastine, or doxorubicin. ${ }^{123}{ }^{124} \propto$ Interferon was also effective. ${ }^{125}$ The overall prognosis was very poor, however, with a median survival of four to six months only. Recently, better results have been obtained with combination chemotherapy with bleomycin, vincristine, and doxorubicin. In a recent study 20 patients with pulmonary Kaposi sarcoma received two weekly cycles of bleomycin $10 \mathrm{mg} / \mathrm{m}^{2}$ and vincristine $2 \mathrm{mg}$. Doxorubicin $20 \mathrm{mg} / \mathrm{m}^{2}$ was reserved for patients with severe disease. Twelve patients had a partial or complete response and their median survival was 12 months. The eight non-responders had a median survival of only six months. Shorter survival was associated with pleural effusion or a CD4 lymphocyte count below $0.1 \times 10^{9} / 1 . .^{126} 127$ The combination of vincristine, bleomycin, and zidovudine in a further study was shown to produce partial or complete response in about $80 \%$ of patients treated. ${ }^{128}$ These responses to treatment are relatively short lived so that combination chemotherapy provides palliation only.

There has been renewed interest in treatment with $\alpha$ interferon in conjunction with zidovudine, uncontrolled studies showing an increase in survival and also a reduction in opportunist infections. ${ }^{129-131}$ Treatment of pleural effusions, which may be very large, is problematic. Effusion may result from either sarcoma in the visceral pleural or lymphatic obstruction due to sarcoma in mediastinal glands. Pleural effusions tend to occur as a late manifestation of extensive parenchymal disease; chemical pleurodesis is rarely successful and radiotherapy has not been shown to be of value. ${ }^{113}$

We thank Dr Ashley Woodcock for helpful comments and Miss Susie Mace for typing the manuscript.

1 Biggar RJ. Preventing AIDS now. BMJ 1991;303:1150-1. 2 Rutherford GW, Lifson AR, Hersol NA. Course of HIV-1 infection in a cohort of homosexual and bisexual men: an 11 year follow up study. $B M J 1990 ; 301: 1183-8$.

3 Lee CA, Phillips AN, Elford J, et al. Progression of HIV disease in a haemophilic cohort followed for 11 years and the effect of treatment. BMJ 1991;303:1093-6.
4 Phillips AN, Lee CA, Elford J, et al. Serial CD4 lymphocyte counts and development of AIDS. Lancet 1991; 337:389-92.

5 Moss AR, Bacchetti P, Osmond D, et al. Seropositivity for HIV and the development of AIDS or AIDS related condition: three year follow up of the San Francisco General Hospital cohort. BMJ 1988;196:745-50.

6 Simmonds P, Beatson D, Cuthbert RJG, et al. Determinants of HIV disease progression: six year longitudinal study in the Edinburgh haemophilia/HIV cohort. Lancet 1991;338:1159-63.

7 Beck EJ, French PD, Helbert $\mathrm{MH}$, et al. Improved outcome of Pneumocystis carinii pneumonia in AIDS patients. A multifactorial treatment effect. International Journal of Sexually Transmitted Diseases and AIDS (in press).

8 Beck EJ, French PD, Helbert, et al. Empirically treated pneumocystis pneumonia in London 1983-89: two of a kind. International Journal of Sexually Transmitted Diseases and $A I D S$ (in press).

9 Girard PM, Pocidalo JJ, Murray JF. Primary prophylaxis against common infectious diseases in persons with human immunodeficiency virus infection. Am Rev Respir Dis 1991;143:447-50.

10 Schlam HT, Yancowitz SR. Haemophilus influenzae pneumonia in young adults with AIDS, ARC, or risk of AIDS. Am J Med 1989;86:11-4.

11 Rolston RVI, Uribe-Botero G, Mansell PWA. Bacterial infections in adult patients with the acquired immune deficiency syndrome (AIDS) and AIDS-related complex. Am J Med 1987;83:604-5.

12 Witt DJ, Craven DE, McCabe WR. Bacterial infections in adult patients with the acquired immune deficiency syndrome (AIDS) and AIDS-related complex. $\mathrm{Am}$ Med 1987;82:900-6.

13 Selwyn PA, Feingold AR, Hartel D, et al. Increased risk of bacterial pneumonia in HIV infected intravenous drug users without AIDS. AIDS 1988;2:267-72.

14 Chaisson RE. Bacterial pneumonia in patients with human immunodeficiency virus infection. Sem Respir Inf 1989;4:133-8.

15 Magnenat JL, Nicod LP, Auckenthaler R, et al. Mode of presentation and diagnosis of bacterial pneumonia in human immunodeficiency virus infected patients. $A m$ Rev Respir Dis 1991;144:917-22.

16 Jeffrey AA, Miller RF. Bacterial pneumonia in homosexua patients positive for HIV [abstract]. Thorax 1991, 46:771P.

17 Parkin J, Helbert $M$, Hughes $M$, et al. Immunoglobulin $G$ subclass deficiency and susceptibility to pyogenic infections in patients with AIDS and AIDS related complex. AIDS 1989;3:37-9.

18 Huang K-L, Ruben FL, Rinaldo CR, et al. Antibody responses after influenza and pneumococcal immunisation in HIV-infected homosexual men. JAMA 1987; tion in HIV-inf

19 Centers for Disease Control. Recommendations of the Immunisation Practice Advisory Committee. Pneumococcal polysaccharide vaccine. Mortality and Morbidity Weekly Reports 1989;38:64-76.

20 Murray J, Mills J. State of the Art: pulmonary infections, complications of human immunodeficiency virus infection. Part 1. Am Rev Respir Dis 1990;141:1356-72.

21 Murray J, Mills J. State of the Art: pulmonary infections, complications of human immunodeficiency virus infection. Part 2. Am Rev Respir Dis 1990;141:1582-98.

22 Hoover DR, Graham NMH, Bacellar H, et al. Epidemiologic patterns of upper respiratory illness and Pneumocystis carinii pneumonia in homosexual men. Am Rev Respir Dis 1991;83:604-5.

23 Coplan NL, Shimony RY, Iochim HL, et al. Primary pulmonary hypertension associated with human immunodeficiency viral infection. Am J Med 1990;89. 96-9.

24 Himelman RB, Dohrmann M, Goodman P, et al. Severe pulmonary hypertension and cor pulmonale in the acquired immunodeficiency syndrome. Am J Cardiol acquired immun

25 Speich R, Jenni R, Opravil M, et al. Primary pulmonary hypertension in HIV infection. Chest 1991;100:1268-71.

26 Grundy JE, Shanley JD, Griffiths PD. Is cytomegalovirus interstitial pneumonitis in transplant recipients an immunopathological condition? Lancet 1987;ii:996-9.

27 Schooley RT. Cytomegalovirus in the setting of infection with human immunodeficiency virus. Rev Infect Dis 1990;12(suppl 7):811-9.

28 Davis ME, Kenney SC, Kamine J, et al. Immediate-early gene region of human cytomegalovirus trans-activates the promoter of human immunodeficiency virus. Proc Natl Acad Sci USA 1987;84:8642-6.

29 Rando RF, Srinivasan A, Feingold J, et al. Characterisation of multiple molecular interactions between human cytomegalovirus (HCMV) and human immunodeficiency virus type-1. (HIV-1). Virology 1990;176:87-97.

30 Wallace JM, Hannah J. Cytomegalovirus pneumonitis in patients with AIDS: findings in an autopsy series. Chest 1987;82:198-203.

31 Millar AB, Paton G, Miller RF, et al. Cytomegalovirus in 
the lungs of patients with AIDS: respiratory pathogen or passenger? Am Rev Respir Dis 1990;141:1474-7.

32 Bower M, Barton SE, Nelson MR, et al. The significance of the detection of cytomegalovirus in the bronchoalveolar lavage fluid in AIDS patients with pneumonia. AIDS 1990;4:317-20.

33 Clarke JR, Fleming J, Donegan K, et al. Effect of HIV-1 and cytomegalovirus in bronchoalveolar lavage cells on the transfer factor for lung carbon monoxide in AIDS patients. AIDS 1991;5:1333-8.

34 Murray JF, Felton CP, Garay SM, et al. Pulmonary complications of the acquired immunodeficiency syndrome: report of a National Heart, Lung and Blood Institute Workshop. N Engl J Med 1984;310:1682-8.

35 Stover DE, White DA, Romano PA, et al. Spectrum of pulmonary disease associated with the acquired immunodeficiency syndrome. Am J Med 1985;78: 429-37.

36 Miles PR, Baughman RP, Linnemann CC. Cytomegalovirus in the bronchoalveolar lavage fluid of megalovirus in the bronchoalveolar lavage

37 Broaddus C, Dake MD, Stulbarg MS, et al. Bronchoalveolar lavage and transbronchial biopsy for the diagnosis of pulmonary infections in the acquired immunodeficiency syndrome. Ann Intern Med 1985;102:747-52.

38 Youle M, Gazzard B, Chanas A, et al. Treatment with foscarnet of presumed CMV pneumonitis in patients with AIDS: a double blind placebo controlled study [abstract]. In: Proceedings of IV International Conference on AIDS. Stockholm: 1988:abst 3587.

39 Jackobson MA, Mills J, Rush J, et al. Morbidity and mortality of patients with AIDS and first-episode Pneumocystis carinii pneumonia unaffected by concomitant pulmonary cytomegalovirus infection. $A m R e v$ Respir Dis 1991;144:6-9.

40 Fitzgerald JM, Grzybowski S, Allen EA. The impact of human immunodeficiency virus infection on tuberculosis and its control. Chest 1991;100:191-200.

41 Styblo K, Enarson DA. The impact of infection with human immunodeficiency virus on tuberculosis. In Mitchell DM, ed. Recent advances in respiratory medicine 5. Edinburgh: Churchill Livingstone, 1991:147-62.

42 Harries AD. Tuberculosis and human immunodeficiency virus infection in developing countries. Lancet 1990; 335:387-9.

43 Chaisson RE, Slutkin G. Tuberculosis and human immunodeficiency virus infection. J Infect Dis 1989 159:96-9.

44 Centers for Disease Control. Tuberculosis final dataUnited States 1986. Mortality and Morbidity Weekly Reports 1988;36:817-20.

45 Fournier AM, Dickinson GM, Erdfrocht IR, et al. Tuberculosis and non-tuberculosis mycobacteriosis in patients with AIDS. Chest 1988;93:772-5.

46 Reider HL, Cauthen GM, Bloch AB, et al. Tuberculosis and acquired immunodeficiency syndrome-Florida. Arch Intern Med 1989;149:1268-73.

47 Pitchenik AE, Cole C, Russell BW, et al. Tuberculosis, atypical mycobacteriosis and the acquired immunodeficiency syndrome among Haitian and non-Haitian patients in South Florida. Ann Intern Med 1984;101 641-5.

48 Sunderam G, McDonald RJ, Maniatis T, et al. Tuberculosis as a manifestation of the acquired immunodeficiency syndrome (AIDS). JAMA 1986;256:362-6.

49 Chaisson RE, Schecter GF, Thener CP, et al. Tuberculosis in patients with the acquired immunodeficiency syndrome. Am Rev Respir Dis 1987;136:570-4.

50 Fife D, Crane GL, Bishburg E. Cumulative AIDS incidence and altered mortality from mycobacterial disease: New Jersey. Am Rev Respir Dis 1991;143:717-20.

51 Long $R$, Scalcini M, Monfreda J, et al. Impact of human immunodeficiency virus type 1 on tuberculosis in rural Haiti. Am Rev Respir Dis 1991;143:69-73.

52 Selwyn PA, Hartel D, Lewis VA, et al. A prospective study of the risk of tuberculosis among intravenous drug users with human immunodeficiency virus infection. $N$ Engl Med 1989;320:545-50.

53 Pitchenik AE. Tuberculosis control and the AIDS epidemic in developing countries. Ann Intern Med 1990;113:89-91.

54 Widy-Wirsky R, Berkley S, Downing R, et al. Evaluation of the WHO clinical case definition for AIDS in Uganda. JAMA 1988;260:3286-9.

55 Berkley SF, Widy-Wirsky R, Okwane SI, et al. Risk factors associated with HIV infection in Uganda. $J$ Infect Dis 1989;160:22-30.

56 Eriki PP, Okwera A, Aisu T, et al. The influence of human immunodeficiency virus infection on tuberculosis in Kampala Uganda. Am Rev Respir Dis 1991;143:185-7.

57 Colebunders RL, Ryder RW, Nzilambi N, et al. HIV infection in patients with tuberculosis in Zaire. Am Rev Respir Dis 1989;139:1082-5.

58 Willame JC, Prignot J, Nsinga MM, et al. Enquête tuberculinique et radiographique transversale sur l'endémie tuberculeuse à Kinshasa, Zaire (1978-1979). Ann Soc Belge Med Trop 1981;61:489-501.

59 Perriens JH, Colebunders RL, Karahunga C, et al.
Increased mortality and tuberculosis treatment failure rate among HIV seropositive compared with HIV seronegative patients with pulmonary tuberculosis treated with standard chemotherapy in Kinshasa, Zaire. Am Rev Respir Dis 1991;144:750-5.

60 Ryder RW, Nsa W, Hassig SE, et al. Perinatal transmission of the human immunodeficiency virus type 1 to infants of seropositive women in Zaire. $N$ Engl $J$ Med 1989; 320:1637-42.

61 Braun MM, Badi N, Ryder RW, et al. A retrospective cohort study of the risk of tuberculosis among women of childbearing age with HIV infection in Zaire. Am Rev Respir Dis 1991;143:501-4.

62 Standaert B, Niragira F, Kadende $P$, et al. The association of tuberculosis and HIV infection in Burundi. AIDS Research in Human Retroviruses 1989;5:247-51.

63 Helbert M, Robinson D, Buchanan D, et al. Mycobacterial infection in patients infected with the human immunodeficiency virus. Thorax 1990;45:45-8.

64 Watson JM, Fern KJ, Porter JDH, et al. Notifications of tuberculosis in England and Wales 1982-1989. Communicable Disease Reports 1991; (review 2):R13-6.

65 Foley NM, Semple SJG, Miller RF. Tuberculosis and AIDS: is the "white plague" up and coming? [abstract] Thorax 1992;47:223P.

66 Morbidity and Mortality Weekly Reports. Revision of the CDC surveillance case definition for acquired immunodeficiency syndrome. Mortality and Morbidity Weekly Reports 1987;36(suppl):3-155.

67 Pitchenik AE, Fertel D, Bloch AB. Mycobacterial disease: epidemiology, diagnosis, treatment and prevention. Clin Chest Med 1988;9:425-41.

68 Cegielski JP, Ramaiya K, Lallinger GJ, et al. Pericardial disease and HIV in Dar-es-Salaam, Tanzania. Lancet 1990;335:209-12.

69 Elliott AM, Luo N, Tembo G, et al. Impact of HIV on tuberculosis in Zambia: a cross sectional study. $B M J$ 1990;301:412-5.

70 Hill AR, Premkumar S, Brustein S, et al. Disseminated tuberculosis in the acquired immunodeficiency syndrom era. Am Rev Respir Dis 1991;144:1164-70.

71 Long $R$, Maycher $B$, Scalcini $M$, et al. The ches roentgenogram in pulmonary tuberculosis patients seropositive for human immunodeficiency virus type 1 . Seropositive for human

72 Pitchenik AE, Rubinson $H A$. The radiographic appearance of tuberculosis in patients with the acquired immunodeficiency syndrome (AIDS) and pre-AIDS. Am Rev Respir Dis 1985;131:393-6.

73 Klein NC, Duncanson FP, Lenox TH, et al. Use of mycobacterial smears in the diagnosis of pulmonary tuberculosis in AIDS/ARC patients. Chest 1989;95: tuberculosis

74 Shafer RW, Goldberg T, Sierra M, et al. Frequency of MTB bacteraemia in patients with tuberculosis in an area endemic for AIDS. Am Rev Respir Dis 1989;140:1611-3.

75 Tomlinson DR, Moss F, McCarthy M, et al. Infection with M. tuberculosis in HIV-positive individuals. A retrospective analysis. International Journal of Sexually Transmitted Diseases and AIDS (in press).

76 Small PM, Schecter GF, Goodman PC, et al. Treatment of tuberculosis in patients with advanced human immunodeficiency virus infection. N Engl J Med 1991;324:289.

77 Engelhard D, Stutman HR, Marks MI. Interaction of ketaconazole with rifampin and isoniazid. $N$ Engl J Med 1984;311:1681-3.

78 Willame JC, Nkoko B, Pauwels $P$, et al. Tuberculose et sero-positive anti VIH A, Kinshasa, Zaire. Ann Soc Belg Med Trop 1988;68:165-7.

79 Centers for Disease Control. Tuberculosis and HIV infection: recommendation of the Advisory Committee for the Elimination of Tuberculosis. Mortality and Morbidity Weekly Reports 1989;38:236-50.

80 Centers for Disease Control. Disseminated Mycobacterium bovis infection from BCG vaccination in a patient with acquired immunodeficiency syndrome. Mortality and Morbidity Weekly Reports 1985;34:227-8.

81 World Health Organisation. HIV and routine childhood immunisation. Weekly Epidemiol Record 1987;62:297-9.

82 Citron KM. BCG vaccination in children. BMJ 1990; 301:1275.

83 Braun MM, Truman BI, Maguire B, et al. Increasing incidence of tuberculosis in a prison inmate population: association with HIV infection. JAMA 1989;261:393-7.

84 DiPerri G, Cruciani M, Danzi MC, et al. Nosocomial epidemic of active tuberculosis among HIV-infected patients. Lancet 1989;ii:1052-4.

85 Centers for Disease Control. Transmission of multidrugresistant tuberculosis from an HIV-positive client in a residential substance-abuse treatment facility1991; 40:129-31.

86 Horsburgh CR, Mason UG, Farhi DC, et al. Disseminated infection with Mycobacterium avium intracellulare. Medicine 1985;64:36-48.

87 Armstrong D, Gold JWM, Dryjanski J, et al. Treatment of infections in patients with the acquired immunodeficiency syndrome. Ann Intern Med 1985;103:738-43. 
88 Hawkins CE, Gold JWM, Whimbey E, et al. Mycobaccerium avium complex infections in patients with the acquired immunodeficiency syndrome. Ann Intern Med 1986; 105:184-8.

89 Wallace JM, Hannah JB. Mycobacterium avium complex infection in patients with the acquired immunodeficiency syndrome. Chest 1988;93:926-32.

90 Horsburgh CR, Metchock BG, McGowan JE, et al. Progression to disseminated infection in HIV infected persons colonised with mycobacteria other than tuberculosis. [abstract] $A m$ Rev Respir Dis 1991; 143(suppl):A279.

91 Jacobson MA, Hopewell PC, Yajko DM, et al. Natural history of disseminated Mycobacterium avium complex infection in AIDS. J Infect Dis 1991;164:994-8.

92 Horsburgh CR, Selik RM. The epidemiology of disseminated non-tuberculous mycobacterial infection in AIDS Am Rev Respir Dis 1989;139:4-7.

93 Nassos PS, Yajko DM, Sanders CA, et al. Prevalence of Mycobacterium avium complex in respiratory specimens from AIDS and non-AIDS patients in a San Francisco Hospital. Am Rev Respir Dis 1991;143:66-8.

94 Agins BD, Berman DS, Spicehandber D, et al. Effect of combination therapy with ansamycin, clofazomine, ethambutol, and isoniazid for Mycobacterium avium infection in patients with AIDS. $J$ Infect Dis 1989; 159:784-7.

95 Klatt EC, Jensen DF, Meyer PR. Pathology of Mycobacterium avium intracellulare infection in acquired terium avium intracellulare infection in acquired immunode

96 Welch K, Finkeleiner W, Acpers CE. Autopsy findings in the acquired immunodeficiency syndrome. JAMA 1984 252:1152-9.

97 Wilkes MS, Fortin AH, Folit JL. Value of necropsy in acquired immunodeficiency syndrome. Lancet 1988;ii: 85-8.

98 Chin J, Nussbaum J, Bozette S, et al. Treatment of disseminated Mycobacterium avium complex infection in AIDS with amikacin, ethambutol, rifampicin and ciprofloxacin. Ann Intern Med 1990;113:358-61.

99 Hoy J, Mijch A, Sandland M, et al. Quadruple drug therapy for Mycobacterium avium intracellulare bactherapy for Mycobacterium avium intracellulare bac-

100 Horsburgh CR. Current concepts. Mycobacterium avium complex infection in the acquired immunodeficiency syndrome. N Engl J Med 1991;324:1332-8.

101 Kiehn TE, Cammarata R. Laboratory diagnosis of mycobacterial infections in patients with acquired immunodeficiency syndrome. J Clin Microbiol 1986; 24:708-11.

102 American Thoracic Society. Official statement on diagnosis and treatment of disease caused by non-tuberculous mycobacteria. Am Rev Respir Dis 1990;142:940-63.

103 Heifets LB, Iseman MD. Individualised therapy versus standard regimens in the treatment of Mycobacterium avium infections. Am Rev Respir Dis 1991;144:1-2.

104 Wallace RJ, Glassroth J, O'Brien R. A plea for clinical trials to resolve the issue of optimal therapy in the treatment of Mycobacterium avium infection. Am Rev Respir Dis 1991; 144:3-4.

105 Naik S, Ruck $R$. In vitro activities of several new macrolide antibiotics against Mycobacterium avium complex. Antimicrob Agents Chemother 1989;33:1614-6.

106 Young LS, Wiviott L, Wu M, et al. Azithromycin for the treatment of Mycobacterium avium intracellulare complex infection in patients with AIDS. Lancet 1991, 338:1107-9.

107 Centers for Disease Control. Update: Acquired immunodeficiency syndrome (AIDS)-United States. Mortality and Morbidity Weekly Reports 1986;35:17-21.

108 Haverkar HW, Drotman DP, Morgan M. Prevalence of Kaposi's sarcoma among patients with AIDS. $N$ Engl $J$ Med 1985;313:1518.

109 Jarlais DC, Marmor M, Thomas P, et al. Kaposi's sarcoma among four different AIDS risk groups. N Engl J Med
1984;310:119.

110 Meduri EU, Stover DE, Lee M, et al. Pulmonary Kaposi's sarcoma in the acquired immune deficiency syndrome. Am J Med 1986;81:11-8.

111 Ognibene FP, Sters RO, Macher AM, et al. Kaposi's sarcoma causing pulmonary infiltrates and respiratory failure in the acquired immunodeficiency syndrome. Ann Intern Med 1985;102:471-5.

112 Zibrak JD, Silvestri RC, Costello R, et al. Bronchoscopic and radiologic features of Kaposi's sarcoma involving the respiratory system. Chest 1986;90:476-9.

113 O'Brien RF. Pulmonary and pleural Kaposi's sarcoma in AIDS. Semin Respir Med 1989;10:12-20.

114 Talavera $W$, Wasser L, Villamena $P$, et al. Primary pleuropulmonary Kaposi's sarcoma in AIDS [abstract]. Am Rev Respir Dis 1988;137:A287.

115 Bach MC, Bagwell SP, Fanning JP. Primary pulmonary Kaposi's sarcoma in the acquired immunodeficiency syndrome: a cause of persistent pyrexia. $\mathrm{Am} \mathrm{J} \mathrm{Med}$ 1988;85:274-5.

116 Greenberg JE, Fischl MA, Berger JR. Upper airway obstruction secondary to acquired immunodeficiency syndrome-related Kaposi's sarcoma. Chest 1985;88: 638-40.

117 Silver MA, Macher AM, Reichert C, et al. Cardiac involvement by Kaposi's sarcoma in acquired immunodeficiency syndrome (AIDS). Am J Cardiol 1984;53: 983-6.

118 Shaw RJ, Roussak C, Forster SM, et al. Lung function abnormalities in patients infected with the human immunodeficiency virus with and without overt pneumonitis. Thorax 1988;43:436-40.

119 Hamm PG, Judson MA, Aranda CP. Diagnosis of pulmonary Kaposi's sarcoma with fibreoptic bronchoscopy and endobronchial biopsy. Cancer 1987;59:807-10.

120 Pitchenik AE, Fischl MA, Saldanda MJ. Kaposi's sarcoma of the tracheobronchial tree. Chest 1985;87:122-4.

121 Touboul JL, Mayaud CM, Fouret P, et al. Pulmonary lesions in Kaposi's sarcoma, intra alveolar haemorrhage, and pleural effusion. Ann Intern Med 1985;103:808.

122 Hughes-Davies L, Kocjan G, Spittle MF, et al. Occult alveolar haemorrhage in bronchopulmonary Kaposi's sarcoma. J Clin Pathol (in press).

123 Volberding PA. Kaposi's sarcoma and the acquired immunodeficiency syndrome. Med Clin North Am 1986; 70:665-75.

124 Laubenstein LJ, Kregel RL, Odajnyk C, et al. Treatment of epidemic Kaposi's sarcoma with etoposide or a combination of doxorubicin, bleomycin and vinblastine. $J$ Clin Oncol 1984;2:1115-24.

125 Volberding PA, Mitsuyasu RT, Golando JP, et al. Treatment of Kaposi's sarcoma with interferon alpha-2h ment of Kaposi's sarcoma with
(intron A). Cancer 1987;59:620-5.

126 Gill PS, Akil B, Co.letti P, et al. Pulmonary Kaposi's sarcoma: clinical findings and results of therapy. $A m J$ Med 1989;87:57-61.

127 Gill PS, Rarick MU, Espina B, et al. AIDS-related Kaposi's sarcoma. Cancer 1990;65:1074-8.

128 Rarick MU, Gill PS, Montgomery T, et al. Treatment of epidemic Kaposi's sarcoma with combination chemoepidemic Kaposi's sarcoma with combination ch

129 Kovacs JA, Deyton L, Davey R, et al. Combined zidovudine and interferon- $\alpha$ therapy in patients with Kaposi's sarcoma and AIDS. Ann Intern Med 1990;111:280-7.

130 Krown S, Gold JWM, Niedzwiecki D, et al. Interferon- $\alpha$ with zidovudine: safety tolerance and clinical and
virological effects in patients with Kaposi's sarcoma associated with AIDS. Ann Intern Med 1990;112: 812-21.

131 Fischl MA, Uttamchandani RB, Resnick L, et al. A phase 1 study of recombinant human interferon- $\alpha$ or human lymphoblastoid interferon- $\alpha$ and concomitant zidovudine in patients with AIDS-related Kaposi's sarcoma. Journal of Acquired Immune Deficiency Syndrome 1991;4:1-10. 